\title{
Transcription Termination
}

National Cancer Institute

\section{Source}

National Cancer Institute. Transcription Termination. NCI Thesaurus. Code C28615.

Transcription Termination is the cessation of cellular activities involved in the synthesis a nascent RNA transcript. 